\title{
Glutamine metabolism in cancer therapy
}

\author{
Tra-Ly Nguyen, Raúl V. Durán \\ Institut Européen de Chimie et Biologie, INSERM U1218, Université de Bordeaux, 2 Rue Robert Escarpit, 33607 Pessac, \\ France.
}

Correspondence to: Dr. Raúl V. Durán, Institut Européen de Chimie et Biologie, INSERM U1218, Université de Bordeaux, 2 Rue Robert Escarpit, 33607 Pessac, France. E-mail: raul.duran@inserm.fr

How to cite this article: Nguyen TL, Durán RV. Glutamine metabolism in cancer therapy. Cancer Drug Resist 2018;1:126-38. http://dx.doi.org/10.20517/cdr.2018.08

Received: 28 Jun 2018 First Decision: 23 Jul 2018 Revised: 21 Aug 2018 Accepted: 3 Sep 2018 Published: 19 Sep 2018

Science Editors: Elisa Giovannetti, Jose Antonio Rodriguez Copy Editor: Yuan-Li Wang Production Editor: Huan-Liang Wu

\begin{abstract}
The amino acid glutamine plays a key role in the metabolism of highly proliferating cells. During malignant transformation, cancer cells modify the consumption and processing of glutamine to sustain cell growth and proliferation. In some cases, these cancer cells become addicted to glutamine. Thus, targeting the metabolism of glutamine has been developed during last years as a potential strategy against cancer. In this review, we summarized the last advances in our knowledge about the role of glutamine metabolism in cancer therapy.
\end{abstract}

Keywords: Cancer, glutamine, glutamoptosis, metabolism, mammalian target of rapamycin

\section{INTRODUCTION}

Since the discovery of the "Warburg effect" about the reprogramming of glucose metabolism in the 1920s, there is a massive interest in understanding cancer metabolism for therapeutic benefits. Glucose and glutamine are two most important nutrients used by cancer cells for their proliferation and growth. While the glycolytic pathway produces ATP and metabolic intermediates for biosynthesis, glutamine metabolism can supply amino acids, nucleic acids and glutathione necessary for cell proliferation. In this review, we describe the metabolic transformation in cancer cells, then summarize different roles of glutamine in cancer metabolism in biosynthesis and stress protection. Finally, we discuss potential cancer therapy targeting approaches based on glutamine metabolism.

\section{METABOLIC TRANSFORMATION IN CANCER CELLS}

Among the different hallmarks of cancer ${ }^{[1]}$, metabolic transformation plays a key role in the adaptation of

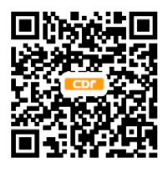


cancer cells to a changing environment. Cancer cells harbor oncogenic mutations, leading to an increase in nutrient uptake, and altering their metabolism to support anabolic processes for cell growth and proliferation.

\section{Uptake}

In order to guarantee a rapid cell proliferation, cancer cells first need to increase the uptake of nutrients from the extracellular environment. Glucose and glutamine are two main nutrients that cancer cells uptake from extracellular environment. Cancer cells become easily "addicted" to glucose and glutamine, as their withdrawal can induce cell death. Through the catabolism of glucose and glutamine, the cells produce both carbon intermediates as building blocks and reducing power for macromolecules production and ATP generation. The increase in glucose consumption by cancer cells was first described by Warburg ${ }^{[2]}$. He saw that cancer cells consume 10 times more glucose than non-proliferating normal cells, and they convert glucose to lactate even in the presence of oxygen and fully functioning mitochondrial respiration. The socalled "Warburg effect" (or aerobic glycolysis) has become a well-known and common metabolic phenotype allowing tumors to fulfil the energetic requirement for cell growth ${ }^{[3]}$. Positron emission tomography (PET)-based imaging of the high uptake of a radioactive fluorine-labeled glucose analogue $18 \mathrm{~F}$-fluorodeoxyglucose (18F-FDG) by cancer cells is used as an imaging tool for the detection of several cancers and for the monitoring of treatment response ${ }^{[4]}$. Cancer cells acquire oncogenic alterations to increase glucose uptake, independently of external stimuli. For instance, PI 3 K/AKT pathway promotes both the expression of glucose transporter GLUT1 mRNA and the translocation of GLUT1 protein from endomembranes to the cell surface ${ }^{[5,6]}$. Furthermore, AKT potentiates the activity of hexokinase and phosphofructokinase enzymes, which catalyse rate-limiting steps of glycolysis, in order to induce glucose consumption to branching pathways ${ }^{[7-9]}$. Additionally, GLUT1 mRNA expression is upregulated by Src or Ras protein, mostly in the presence of two enhancer elements in the gene ${ }^{[10]}$. Thus, oncogenic signaling pathways, which are often upregulated in cancer, share also another common point to induce glucose import.

High glutamine demand was first described by Eagle ${ }^{[11]}$, when he saw that cultured HeLa cells required 10 to 100 times more of glutamine than any other amino acid. Not only as carbon source, glutamine is also a nitrogen source for de novo biosynthesis of different nitrogen-containing building blocks, such as purine and pyrimidine nucleotides, glucosamine-6-phosphate, and nonessential amino acids. Moreover, glutamine participates in the uptake of essential amino acids from extracellular environment. For example, leucine is imported through the plasma membrane by the amino acid antiporter LAT1/SLC7A5 in coupling with an efflux of glutamine ${ }^{[12]}$. Indeed, LAT1/SLC7A5 expression has been reported to be increased in several cancer types ${ }^{[13,14]}$. Due to the high demand of glutamine, this amino acid is also used for imaging based on $18 \mathrm{~F}-$ labeled glutamine tracers in preclinical and clinical studies, especially when the use of $18 \mathrm{~F}-\mathrm{FDG}$ is not feasible, like in the brain ${ }^{[15,16]}$. The mechanisms of glutamine uptake regulation are still being identified. The principal regulator of glutamine utilization is the transcription factor $c-m y c$, which is often upregulated in proliferating cells ${ }^{[17,18]}$. Indeed, $c$-myc induces the transcription of glutamine transporters, such as SLC1A5/ASCT2, and also promotes the expression of glutamine-catabolized enzymes such as glutaminase 1 (GLS1) and carbamoyl-phosphate synthetase 2 - aspartate transcarbamylase - dihydroorotase (CAD), in order to encourage glutamine uptake by converting glutamine to glutamate ${ }^{[19-21]}$. In addition, glutamine uptake can be negatively regulated by retinoblastoma $(\mathrm{Rb})$ tumor suppressor family, whose deletion increases glutamine uptake via the E2F-dependent upregulation of SLC1A5/ASCT2 and GLS1 ${ }^{[22]}$. Thus, glutamine consumption is supported by the activity of $c-m y c$ and $E 2 F$ transcription factors which regulate cell cycle, to ensure the cellular access to glutamine for DNA replication.

\section{Metabolic intermediates for biosynthesis}

Despite the original idea of Warburg ${ }^{[2]}$ that aerobic glycolysis was originated as a consequence of mitochondrial dysfunction, subsequent studies showed that mitochondria of cancer cells are still functional and able to conduct oxidative phosphorylation. To adapt to a rapid proliferation, cancer cells need building blocks, 
intermediary metabolites and reducing power as NADPH. Glycolysis can robustly provide these demands, providing glycolytic intermediates which are diverted into branching pathways. A prominent case of a pathway which uses glycolytic intermediates is the pentose phosphate pathway (PPP). Glucose-6-phosphate produced from glucose can be oxidized by glucose-6-phosphate dehydrogenase to generate NADPH and ribose-5-phosphate, necessary for nucleotide synthesis. PPP is often upregulated in tumors and their enzymes are frequently overexpressed in cancer ${ }^{[2,24]}$. Another important case is the use of glycolytic 3-phosphoglycerate as a precursor for the serine and glycine metabolism through the one-carbon cycle. Several studies have revealed that the gene encoding 3-phosphoglycerate dehydrogenase, the rate-limiting serine biosynthesis enzyme, is amplified in breast cancers and melanomas ${ }^{[25,26]}$. Serine and glycine metabolism, derived from glycolytic 3-phosphoglycerate, provide advantages for cell growth, such as nucleotide synthesis, DNA methylation, glutathione production and NADPH generation.

After feeding all branching pathways, the excess of glycolytic flux is converted to lactate to preserve a sufficient pool of NAD+ for glycolysis and also to avoid the tricarboxylic acid (TCA) cycle inhibition due to excess NADH. Still, a percentage of pyruvate enters the mitochondria, and a great portion of citrate generated at the TCA cycle from this pyruvate will be secreted to the cytosol through the mitochondrial tricarboxylate carrier. Once at the cytosol, citrate is transformed to acetyl-CoA and oxaloacetate, which is converted to malate for mitochondrial anaplerosis ${ }^{[27,28]}$. Citrate-derived acetyl-CoA is used as a precursor for lipid biosynthesis and protein acetylation.

In addition to glycolytic intermediates, TCA cycle intermediates are also used for biosynthetic precursors accumulation. The first example is citrate-derived acetyl-CoA, whose production is increased by PI3K/ AKT-mediated ATP-citrate lyase (ACLY) enzyme ${ }^{[29]}$. Secondly, the TCA cycle also provides metabolic precursors for the synthesis of nonessential amino acids, such as aspartate and asparagine from oxaloacetate, or proline and arginine from $\alpha$-ketoglutarate. Then, aspartate is used for nucleotide biosynthesis. Indeed, enabling aspartate synthesis is an essential role of the oxidative phosphorylation in cell proliferation ${ }^{[30,31]}$.

Due to the release of citrate to the cytosol, the maintenance of the pool of TCA cycle intermediates needs additional influx, called anaplerosis. The main anaplerotic source in growing cells is glutamine $e^{[32]}$. In $c$ myc-transformed cells, glutamine deprivation could disrupt the TCA cycle and induce cell death, which can be rescued by the addition of oxaloacetate or $\alpha$-ketoglutarate ${ }^{[33]}$. Glutamine-derived $\alpha$-ketoglutarate is oxidized into oxaloacetate to maintain the production of citrate. During hypoxia or under certain oncogenic conditions, $\alpha$-ketoglutarate could be converted directly to citrate (following a reversed TCA cycle), in order to generate the cytosolic acetyl-CoA when glucose-derived acetyl-CoA is insufficient ${ }^{[34]}$.

\section{GLUTAMINE UTILIZATION IN CANCER CELLS}

Glutamine is the most abundant free amino acid in the blood, whose circulating concentration is around $0.5 \mathrm{mmol} / \mathrm{L}^{[35]}$. Despite being a nonessential amino acid, glutamine is physiologically an essential source of carbon and nitrogen for cancer cell proliferation. As discussed above, glutamine uptake is increased specifically in cancer cells that have dysregulated oncogenes and tumor suppressors, such as $c-m y c$. Glutamine is catabolized by different enzymes, including GLS, CAD or glutamine fructose-6-phosphate amidotransferase (GFAT). As an anaplerotic source, glutamine is converted to $\alpha$-ketoglutarate through mitochondrial glutaminolysis. Glutamine is first deamidated to glutamate, in an irreversible reaction catalysed by the enzyme GLS. Then, glutamate is deaminated to $\alpha$-ketoglutarate by the enzyme GLUD1/glutamate dehydrogenase (GDH) or by several aminotransferases to produce other non-essential amino acids. Subsequently, $\alpha$-ketoglutarate enters the TCA cycle to replenish the mitochondrial citrate pool. GLS is the rate-limiting enzyme of glutaminolysis, whose regulation is controlled tightly. There are two isoforms of GLS which are encoded by two genes in mammals, the kidney-type GLS1 and the liver-type GLS2. GLS1 is the main isoform expressed in cancer cells and has been shown to be upregulated in a wide variety of cancers, includ- 


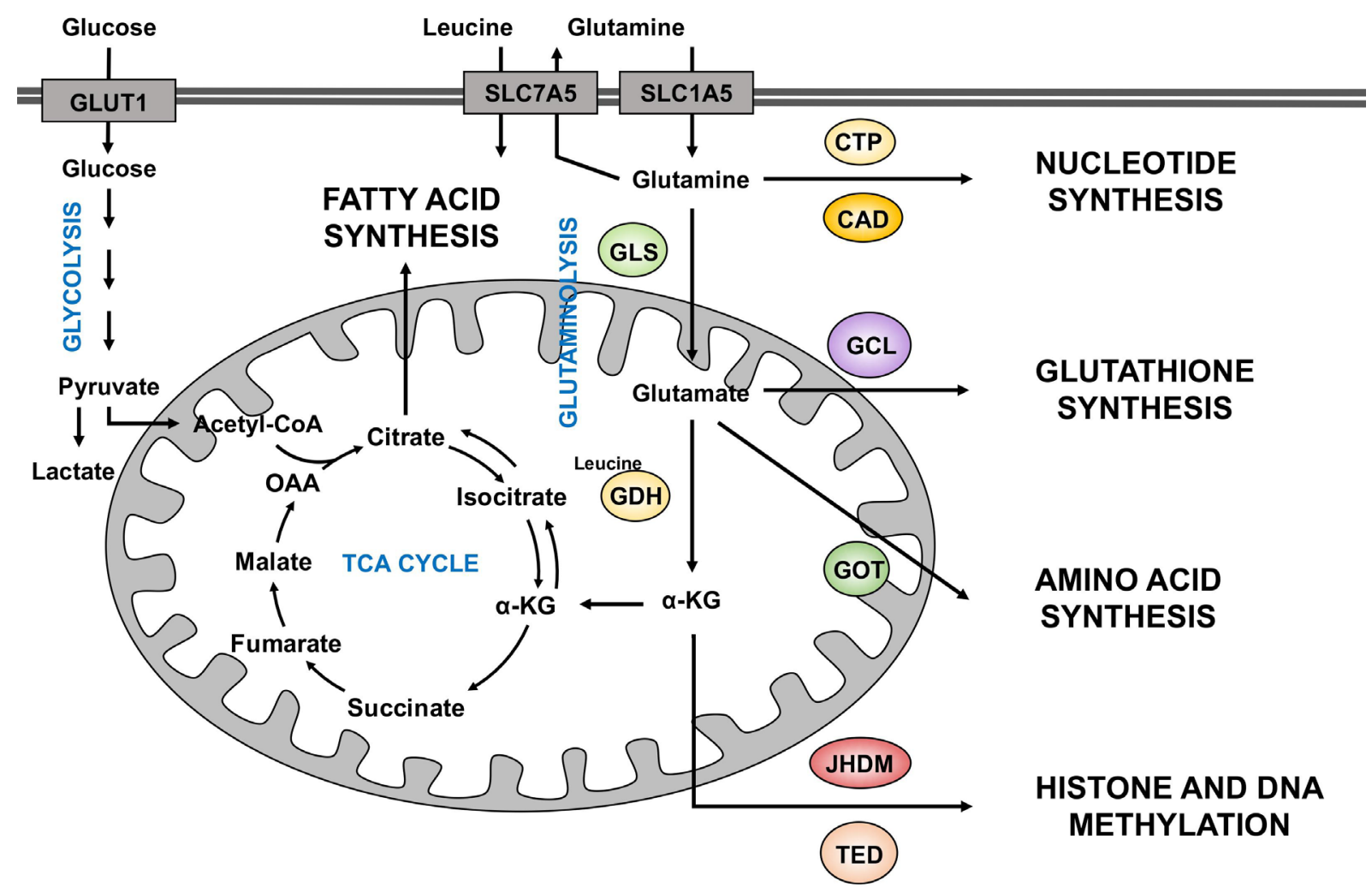

Figure 1. Different uses of glutamine in cancer cells. Glutamine enters the cells through transporters such as SLC1A5. Once inside the cell, glutamine can contribute to nucleotide biosynthesis directly (through CAD for example) or is converted to glutamate by GLS. Moreover, it can also be exported outside of the cell for the import of leucine, a coactivator of GDH. Then, glutamate can be converted to $\alpha$-KG by GDH. Glutamate can contribute to the synthesis of glutathione through the activity of different enzymes, such as GCL. Amino acid synthesis is supported by the aminotransferases (such as GOT) which converts glutamate to $\alpha$-KG. Glutamine-derived $\alpha$-KG can enter the TCA cycle to produce energy for the cell or proceed backwards via the reductive carboxylation to provide an alternative source of lipid synthesis. Moreover, $\alpha-K G$ is a co-substrate of dioxygenase enzymes (such as JHMD and TED) in the regulation of histone and DNA methylation. $\alpha$-KG: $\alpha$-ketoglutarate; CAD: carbamoyl-phosphate synthetase 2 aspartate transcarbamylase, and dihydroorotase; CTP: CTP synthetase; GCL: glutamate-cysteine ligase; GLS: glutaminase; GDH: glutamate dehydrogenase; GOT: glutamate-oxaloacetate transaminase; JHMD: Jumonji C histone demethylases; TED: TET DNA demethylases

ing breast, lung, cervix and brain ${ }^{[36]}$. GLS1 is inhibited by its product, glutamate ${ }^{[37]}$. GDH activity is also increased in tumor cells. Leucine, a key amino acid from a signaling point of view, is an allosteric activator of GDH, inducing the production of $\alpha$-ketoglutarate and preventing GLS inhibition by glutamate accumulation ${ }^{[38]}$. As discussed above, glutamine is imported by the transporter SLC1A5, while leucine is taken up through the bidirectional antiporter SLC7A5 which exports glutamine out of the cell. Thus, glutamine modulates glutaminolysis in combination with leucine [Figure 1].

Glutamine can be synthetized by the cells through GLUL/glutamine synthetase (GS) which catalyses the condensation reaction between glutamate and ammonia in an ATP-dependent manner and generates glutamine. In mammals, GS is mostly expressed in the liver, brain, and muscle. GS has been found to be a marker of hepatocellular carcinoma (HCC) and its elevated expression may enhance the metastatic potential in HCC patients ${ }^{[39]}$. Moreover, GS expression correlates with a poor survival in glioblastoma patients ${ }^{[40]}$.

\section{Carbon donor}

Glutamine-derived carbon incorporation into the TCA cycle is necessary for the bioenergetic needs and biosynthetic precursors of the cells. Glutamine-derived $\alpha$-ketoglutarate can fuel fatty acids synthesis through the reductive carboxylation mediated by isocitrate dehydrogenase (IDH). IDH catalyzes the oxidative decarboxylation of isocitrate to produce $\alpha$-ketoglutarate. As this enzyme catalyzes a reversible reaction 
between isocitrate and $\alpha$-ketoglutarate, the inverse reaction, so called the reductive carboxylation, could occur to maintain TCA cycle intermediates under mitochondria defects. Emerging evidence reported the role of glutamine mediating reductive carboxylation for lipid biosynthesis and also for redox homeostasis in cancer with dysfunctional mitochondria or under hypoxia ${ }^{[3,41-43]}$.

\section{Nitrogen donor}

Glutamine has two atoms of reduced nitrogen, called $\alpha$-nitrogen and $\gamma$-nitrogen. At the level of nucleotide synthesis, glutamine is the nitrogen donor for enzymes in the purine synthesis, including glutamine phosphoribosylpyrophosphate amidotransferase, phosphoribosyl formylglycinamidine synthetase, and guanosine monophosphate synthetase. But glutamine also acts as nitrogen donor, being metabolized by enzymes involved in the synthesis of pyrimidine, including CAD and CTP synthetase. Thus, one glutamine molecule is used in the production of uracil and thymine, two for cytosine and adenine, and three for a guanine base. Besides that, purine and pyrimidine synthesis use also glutamine-derived aspartate, whose supplementation can rescue cell cycle arrest caused by glutamine deprivation ${ }^{[4]}$. Interestingly, only the $\gamma$-nitrogen of glutamine is used for nucleotide synthesis. This nitrogen is also required for the synthesis of NAD, glucosamine-6-phosphate (a precursor for protein glycosylation), and asparagine, a non-essential amino acid that compensates for glutamine deprivation ${ }^{[45]}$.

The $\alpha$-nitrogen of glutamine is used to produce other non-essential amino acids or polyamines via transamination. This reaction is catalysed by a family of aminotransferases to produce alanine $e^{[46]}$, aspartate $e^{[47]}$, serine $e^{[48]}$, proline ${ }^{[49]}$ and ornithine ${ }^{[50]}$. Glutamine is the source of at least $50 \%$ of non-essential amino acids used in protein synthesis by cancer cells ${ }^{[51]}$. It is estimated that glutamine represents on average up to $4.7 \%$ of all amino acid residues in human proteome, but obviously the percentage can differ from protein to protein ${ }^{[52]}$. Hence, glutamine is a key structural building block in the biosynthesis of proteins, nucleotides, non-essential amino acids and polyamines to support biomass accumulation and rapid rates of proliferation.

\section{Redox homeostasis control}

During tumorigenesis, cancer cells encounter oxidative stress continuously. In order to maintain oxidative homeostasis, the cells need to increase their antioxidant capacity. Glutamine metabolism plays a major role in the cellular anti-oxidative mechanisms. Glutamine-derived glutamate is used in the synthesis of glutathione, through the condensation with cysteine and glycine by glutamate-cysteine ligase and glutathione synthetase. Tracer experiments with labelled 13C-glutamine showed an enrichment of $13 \mathrm{C}$ carbons in glutathione. Accordingly, glutamine starvation reduces the glutathione pool of transformed cells ${ }^{[33,53]}$. Moreover, as cystine is an extracellular source of cysteine, cystine uptake is facilitated by the efflux of glutamate via the $\mathrm{xCT}$ antiporter. Once inside the cell, cystine is converted to cysteine, which is then incorporated into glutathione. Indeed, pharmacological inhibition of xCT increases reactive oxygen species (ROS) level and suppresses tumor growth ${ }^{[5,55]}$. However, different investigations showed that $\mathrm{xCT}$ overexpression enhances cell dependency to glutamine or glucose ${ }^{[56-58]}$. Those studies identified a new function of xCT antiporter as a regulator of nutrient flexibility by antagonizing glutamine metabolism. Lastly, glutamine oxidation supports redox homeostasis by supplying carbon to malic enzymes, which produce NADPH. Indeed, in proliferating cells, NADPH is used not only for the lipid synthesis, but also for the reduction of oxidized glutathione (GSSG), protecting the cells from oxidative stres $^{[59]}$.

\section{Chromatin organization}

Glutamine metabolism does not only generate building blocks and energy for cell growth, but also produces co-substrates for cellular regulatory cascades, including those that regulate chromatin organization. Actually, glutamine-derived $\alpha$-ketoglutarate is a co-substrate of dioxygenase enzymes, including the TET family and the jumonji (JMJ) family. Enzymes from the TET and JMJ family catalyse histone and DNA de- 
methylation and they are inhibited by the accumulation succinate, the by-product of these enzymes.

One example of the role of glutamine-derived $\alpha$-ketoglutarate in the regulation of histone and DNA methylation is the neomorphic mutations in IDH1/2 ${ }^{[60,61]}$. Moreover, loss-of-function mutations of succinate dehydrogenase (SDH) increase cellular succinate level, which inhibits DNA demethylation and contribute to tumorigenesis ${ }^{[62,63]}$. Finally, low glutamine in the core region of solid tumors led to histone hypermethylation due to decreased $\alpha$-ketoglutarate level, resulting in cell dedifferentiation and therapeutic resistance in melanoma cells ${ }^{[64]}$. Accordingly, glutamine metabolism plays a role in gene expression through the contribution of $\alpha$-ketoglutarate and succinate to chromatin structure modification.

\section{GLUTAMINE ADDICTION IN CANCER}

Due to the high demand of cancer cells for glutamine, glutamine metabolism is highly regulated in order to maintain cellular biosynthesis and cell growth. Thus, the machinery which regulates glutamine metabolism, needs to be very efficient to increase the cellular access to glutamine. The first mechanism to enhance glutamine acquisition is to induce glutamine uptake. Different glutamine transporters are known, especially SLC1A5/ASCT2 which is controlled by $c-m y c$ or E2F. SLC1A5 is highly expressed in triple-negative breast cancer patients, correlating with poor survival in tumor-bearing mice ${ }^{[65]}$. Besides, other transporters such as SLC38A1/SNAT1 and SLC38A2/SNAT2 can compensate for the depletion of SLC1A5/ASCT2 to contribute to glutamine uptake ${ }^{[6]]}$.

The expression and activity of glutaminolytic enzymes, GLS and GDH, are also tightly regulated. GLS is inhibited by its product glutamate or by inorganic phosphate. Sirtuin 5 (SIRT5), which is overexpressed in lung cancer, decrease the succinylation of GLS to regulate ammonia production and ammonia-induced autophagy ${ }^{[67]}$. The transcription factor $c-m y c$ induces the expression of GLS through the repression of miR-23a and miR-23b62. Furthermore, additional mechanisms are reported to regulate GLS, such as RNA-binding protein regulation of alternative splicing ${ }^{[6,696]}$ or protein degradation through the ubiquitin ligase complex APC/C-Cdh1 during cell cycle progression ${ }^{[70]}$.

Similar to GLS, GDH expression and activity are controlled by different effectors. GDH is allosterically regulated by activators like ADP and leucine, or by inhibitors like ATP, GTP and palmitoyl-CoA ${ }^{[71-73]}$. At the level of post-translational modification, the sirtuin SIRT4 ADP-ribosylates and downregulates GDH in beta-pancreatic cells, thereby decreasing insulin secretion in response to amino acids during caloriesufficient conditions ${ }^{[74]}$. When the extracellular glutamine level is limited, some cancer cell lines are able to induce GS expression in order to escape from glutamine deficient-induced cell death. GS has been found to be overexpressed in some cancers, such as breast cancer or glioblastoma, promoting cell proliferation ${ }^{[40,75]}$. GS transcription is activated by different oncogenic pathways, such as PI3K-PKB-FOXO pathway ${ }^{[76]}, c-$ $m y c^{[77]}$, and Yap1/Hippo pathway ${ }^{[78]}$. Moreover, GS is inactivated by extracellular glutamine because the presence of glutamine induces GS acetylation by $\mathrm{p} 300 / \mathrm{CBP}$ protein, facilitating its ubiquitination and proteasomal degradation ${ }^{[79-81]}$.

Glutamine addiction appears when cancer cells undergo cell death in conditions of glutamine limitation or when glutamine metabolism is inhibited. Many cancer cells which rely on glutamine catabolism for building blocks and energy have been reported to be addicted to glutamine ${ }^{[33,82-84]}$. Glutamine-addicted cells exhibit a decreased survival, or even undergo apoptotic cell death, associated with an increased in DNA damage, an overproduction of ROS or a decreased reduced/oxidized glutathione (GSH/GSSG) ratio. In this context, the oncogenic transcription factor $c-m y c$ plays a key role in the induction of glutamine addiction ${ }^{[1,33]}$. Together, these results suggested that this phenotype could be exploited as cancer therapy through the use of inhibitors of glutaminolytic enzymes or treatment which induce glutamine depletion 
like L-asparaginase.

On the contrary, some cell types show glutamine independence due to the expression of GS. Indeed, glioma cells can synthetize glutamine from glutamate through the activity of GS, maintaining the cell proliferation during glutamine deprivation ${ }^{[85]}$. Also, those cells use glucose as a source for TCA cycle anaplerosis, which can sufficiently provide $\alpha$-ketoglutarate for glutamate and glutamine synthesis. However, the source of the free ammonia necessary for glutamine synthesis is not clear. Alternatively, some cell types can adapt to glutamine withdrawal using asparagine ${ }^{[45,86]}$. Asparagine is indeed playing a role in the exchange of extracellular amino acids, especially serine, arginine and histidine ${ }^{[87]}$. Despite that asparagine is synthetized from glutamine through asparagine synthetase, how cancer cells adapt their metabolic needs during glutamine deprivation remains to be elucidated.

\section{GLUTAMINE METABOLISM AND MTORC1 PATHWAY}

Glutamine metabolism and mammalian target of rapamycin complex 1 (mTORC1) pathway have a tight connection through different mechanisms. The activation of mTORC1 by glutamine and other amino acids is mediated by the Rag GTPase pathway. In addition, glutamine plays a role as the efflux solute for the import of leucine which supports glutamine to activate mTORC1 through glutaminolysis. Moreover, glutamine and leucine cooperate to produce $\alpha$-ketoglutarate through glutaminolysis, which ultimately activates mTORC1. Indeed, short-term glutaminolysis induces mTORC1 lysosomal translocation and activation via the Rag GTPase, then inhibiting autophagy and promoting cell growth ${ }^{[88]}$. Moreover glutaminolysismediated mTORC1 activation required prolyl hydroxylase (PHD) enzymatic activity in a HIF-independent manner ${ }^{[89]}$. Those evidence highlight the role of glutaminolysis-PHD-mTORC1 axis in cancer growth. Besides, glutamine stimulates lysosomal translocation and activation of mTORC1 via the small GTPase ARF1 and v-ATPase in RagA and RagB knockout cells without Ragulator contribution ${ }^{[0]}$.

In agreement with this positive connection between glutaminolysis and mTORC1, FOXO-mediated expression of GS inhibits mTOR signaling by blocking its lysosomal translocation ${ }^{[76]}$. This mechanism is important for maintaining autophagy during nutrient deprivation. Hence, mTORC1 sense glutamine availability in both directions: when glutamine is available, mTORC1 is activated via $\alpha$-ketoglutarate production; but mTORC1 is inactivated when glutamine production is triggered.

The connection between glutamine metabolism and mTORC1 present additional connection branches, as glutamine also plays a role in autophagy-induced mTORC1 restoration during amino acid starvation ${ }^{[91]}$. Thus, glutamine recycling, supported by autophagy, is sufficient to reactivate mTORC1 under restrictive conditions.

However, and paradoxically, long-term glutaminolysis activation during nutritional restriction induces an unbalanced activation of $\mathrm{mTORC} 1$ during nutrient deprivation and promotes apoptosis ${ }^{[92]}$. This type of metabolic-induced cell death is called "glutamoptosis", which supports a tumor suppressor role of glutamine metabolism and mTORC1 (normally known as pro-proliferative inducers) during nutritional imbalance. During glutamoptosis, mTORC1-mediated inhibition of autophagy leads to the accumulation of the autophagic cargo protein sequestosome1/p62 (SQSTM1/p62). Then SQSTM1/p62 interacts with Caspase 8 and activates it to trigger apoptosis. Strikingly, the inhibition of MTORC1 by rapamycin promoted cell survival upon amino acid starvation, which could partially explain the resistance to rapamycin treatment observed in some tumor cells.

Conversely, mTORC1 can regulate glutamine metabolism via different mechanisms. GLS and GDH are both regulated by mTORC1 pathway. Mechanistically, mTORC1 inhibits the transcription of SIRT4 by degrading its activator CREB2 (cyclic adenosine monophosphate responsive element-binding 2), thereby activating $\mathrm{GDH}^{[74,93,94]}$. Also, mTORC1 activate GLS through S6K1/eIF4B-dependent mRNA translation 
of $c-m y c$, leading to GLS expression by repressing miR-23a/b ${ }^{[20,95]}$. Intriguingly, in an organotypic 3D tissue culture model, mTORC1 supports the expression of aminotransferases and the suppression of GDH in proliferating cells ${ }^{[96]}$. Thus, the regulation of glutamine metabolism by $\mathrm{MTORC} 1$ is cell type-dependent and needs to be elucidated further. Moreover, mTORC1 controls glutamine transporters SLC1A4 and SLC1A5 expression, thereby promoting glutamine uptake upon androgen receptor signaling in prostate cancer ${ }^{[97]}$. Interestingly, evidence has shown that glutamine flux through glutamine transporters activates mTOR signaling ${ }^{[98]}$.

In summary, glutamine uptake and metabolism have a tight connection with mTOR signaling. As both pathways are upregulated in many cancers, strategies which target both glutamine metabolism and mTORC1 signaling have shown synergistic effects against cell growth and proliferation ${ }^{[99]}$.

\section{THERAPEUTIC APPLICATIONS}

Given the dependence of cancer cells on glutamine metabolism, targeted therapies have been developed against glutamine metabolism, from glutamine uptake to glutamine-catalysed enzymes. The inhibition of GLS got the attention due to the dysregulation of GLS in a variety of cancers. Indeed, GLS inhibitors have shown promising tumor-suppressive activities in preclinical models for 968 and bis-2-(5-phenylacetamido1,3,4-thiadiazol-2-yl)ethyl sulfide (BPTES), or even in clinical models for CB-839 ${ }^{[100,101]}$. CB-839 has shown efficacy in triple-negative breast cancer and haematological malignancies therapies ${ }^{[101,102]}$. In addition to GLS inhibitors, strategies targeting the conversion of glutamate into $\alpha$-ketoglutarate, such as GDH inhibitors and aminotransferase inhibitors, have also been evaluated in preclinical models of breast cancer and neuroblastoma ${ }^{[103-105]}$.

Nevertheless, most of the compounds are still in the preclinical evaluation stage, or have been directly discarded due to high cytotoxicity. Furthermore, some limitations derived of treatment resistance to targeted therapies against glutamine metabolism have been reported. Induction of pyruvate carboxylase can allow tumor cells to use glucose-derived pyruvate instead of glutamine for anaplerosis, inducing a glutamineindependent growth ${ }^{[106-108]}$. Also, glutamate-derived glutamine production through GS activity could be another mechanism to overcome glutamine addiction and to promote resistance to glutaminolysis inhibitors $^{[85]}$. However, combination therapy between glutamine metabolism inhibitors and other pathway inhibitors induced a stronger apoptotic response and enhanced anti-tumor efficacy. For instance, mTOR inhibition in glioblastoma multiforme cell lines led to a compensatory upregulation of glutamine metabolism, promoting mTOR inhibitor resistance. Thus, combined inhibition of mTOR and GLS resulted in synergistic tumor cell death and growth inhibition in xenograft mouse models ${ }^{[99]}$.

\section{CONCLUSION AND FUTURE PERSPECTIVES}

Glutamine metabolism plays a central role in the regulation of uncontrolled tumor growth by supplying metabolic intermediates as a carbon and nitrogen source and by maintaining the redox homeostasis against oxidative stress during rapid proliferation. The high demand of cancer cells for glutamine results in glutamine addiction phenotype, which becomes a promising target for the design of new therapeutic strategy. Future investigations will elucidate the molecular mechanism of glutamine addiction by identifying the death pathways activating during the impairment of glutamine catabolism or when glutamine is limited. Finally, the development of an effective drug targeting glutamine metabolism is another challenge for the development of novel anticancer therapeutic strategies.

\section{DECLARATIONS}

\section{Authors' contributions}

Wrote the manuscript: Nguyen TL, Durán RV 
Secured funding: Durán RV

\section{Availability of data and materials}

Not applicable.

\section{Financial support and sponsorship}

This work was supported by funds from the following institutions: Institut National de la Santé et de la Recherche Médicale - INSERM, Fondation pour la Recherche Médicale, the Conseil Régional d'Aquitaine, Fondation ARC pour la Recherche sur le Cancer, Ligue Contre le Cancer - Gironde, SIRIC-BRIO, Institut Européen de Chimie et Biologie, and University of Bordeaux.

\section{Conflicts of interest}

All authors declared that there are no conflicts of interest.

\section{Ethical approval and consent to participate}

Not applicable.

\section{Consent for publication}

Not applicable.

\section{Copyright}

(c) The Author(s) 2018.

\section{REFERENCES}

1. Hanahan D, Weinberg RA. Hallmarks of cancer: the next generation. Cell 2011;144:646-74.

2. Warburg O. On the origin of cancer cells. Science 1956;123:309-14.

3. Vander Heiden MG, Cantley LC, Thompson CB. Understanding the warburg effect: the metabolic requirements of cell proliferation. Science 2009;324:1029-33.

4. Almuhaideb A, Papathanasiou N, Bomanji J. 18F-FDG PET/CT imaging in oncology. Ann Saudi Med 2011;31:3-13.

5. Barthel A, Okino ST, Liao J, Nakatani K, Li J, Whitlock JP Jr, Roth RA. Regulation of GLUT1 gene transcription by the serine/threonine kinase Akt1. J Biol Chem 1999;274:20281-6.

6. Wieman HL, Wofford JA, Rathmell JC. Cytokine stimulation promotes glucose uptake via phosphatidylinositol-3 kinase/Akt regulation of Glut1 activity and trafficking. Mol Biol Cell 2007;18:1437-46.

7. Deprez J, Vertommen D, Alessi DR, Hue L, Rider MH. Phosphorylation and activation of heart 6-phosphofructo-2-kinase by protein kinase B and other protein kinases of the insulin signaling cascades. J Biol Chem 1997;272:17269-75.

8. Gottlob K, Majewski N, Kennedy S, Kandel E, Robey RB, Hay N. Inhibition of early apoptotic events by Akt/PKB is dependent on the first committed step of glycolysis and mitochondrial hexokinase. Genes Dev 2001;15:1406-18.

9. Lee JH, Liu R, Li J, Zhang C, Wang Y, Cai Q, Qian X, Xia Y, Zheng Y, Piao Y, Chen Q, de Groot JF, Jiang T, Lu Z. Stabilization of phosphofructokinase 1 platelet isoform by AKT promotes tumorigenesis. Nat Commun 2017;8:949.

10. Murakami T, Nishiyama T, Shirotani T, Shinohara Y, Kan M, Ishii K, Kanai F, Nakazuru S, Ebina Y. Identification of two enhancer elements in the gene encoding the type 1 glucose transporter from the mouse which are responsive to serum, growth factor, and oncogenes. J Biol Chem 1992;267:9300-6.

11. Eagle H. The minimum vitamin requirements of the $\mathrm{L}$ and HeLa cells in tissue culture, the production of specific vitamin deficiencies, and their cure. J Exp Med 1955;102:595-600.

12. Nicklin P, Bergman P, Zhang B, Triantafellow E, Wang H, Nyfeler B, Yang H, Hild M, Kung C, Wilson C, Myer VE, MacKeigan JP, Porter JA, Wang YK, Cantley LC, Finan PM, Murphy LO. Bidirectional transport of amino acids regulates mTOR and autophagy. Cell 2009;136:521-34.

13. Kaira K, Oriuchi N, Imai H, Shimizu K, Yanagitani N, Sunaga N, Hisada T, Tanaka S, Ishizuka T, Kanai Y, Endou H, Nakajima T, Mori M. Prognostic significance of L-type amino acid transporter 1 expression in resectable stage I-III nonsmall cell lung cancer. Br J Cancer 2008;98:742-8.

14. Sakata T, Ferdous G, Tsuruta T, Satoh T, Baba S, Muto T, Ueno A, Kanai Y, Endou H, Okayasu I. L-type amino-acid transporter 1 as a novel biomarker for high-grade malignancy in prostate cancer. Pathol Int 2009;59:7-18.

15. Lieberman BP, Ploessl K, Wang L, Qu W, Zha Z, Wise DR, Chodosh LA, Belka G, Thompson CB, Kung HF. PET imaging of glutaminolysis in tumors by 18F-(2S,4R)4-fluoroglutamine. J Nucl Med 2011;52:1947-55.

16. Venneti S, Dunphy MP, Zhang H, Pitter KL, Zanzonico P, Campos C, Carlin SD, La Rocca G, Lyashchenko S, Ploessl K, Rohle D, Omuro AM, Cross JR, Brennan CW, Weber WA, Holland EC, Mellinghoff IK, Kung HF, Lewis JS, Thompson CB. Glutamine-based 
PET imaging facilitates enhanced metabolic evaluation of gliomas in vivo. Sci Transl Med 2015;7:274ra17.

17. Wang R, Dillon CP, Shi LZ, Milasta S, Carter R, Finkelstein D, McCormick LL, Fitzgerald P, Chi H, Munger J, Green DR. The transcription factor Myc controls metabolic reprogramming upon T lymphocyte activation. Immunity 2011;35:871-82.

18. Wise DR, DeBerardinis RJ, Mancuso A, Sayed N, Zhang XY, Pfeiffer HK, Nissim I, Daikhin E, Yudkoff M, McMahon SB, Thompson CB. Myc regulates a transcriptional program that stimulates mitochondrial glutaminolysis and leads to glutamine addiction. Proc Natl Acad Sci 2008;105:18782-7.

19. Eberhardy SR, Farnham PJ. c-Myc mediates activation of the cad promoter via a post-RNA polymerase II recruitment mechanism. J Biol Chem 2001;276:48562-71.

20. Gao P, Tchernyshyov I, Chang TC, Lee YS, Kita K, Ochi T, Zeller KI, De Marzo AM, Van Eyk JE, Mendell JT, Dang CV. c-Myc suppression of miR-23a/b enhances mitochondrial glutaminase expression and glutamine metabolism. Nature 2009;458:762-5.

21. Mannava S, Grachtchouk V, Wheeler LJ, Im M, Zhuang D, Slavina EG, Mathews CK, Shewach DS, Nikiforov MA. Direct role of nucleotide metabolism in C-MYC-dependent proliferation of melanoma cells. Cell Cycle 2008;7:2392-400.

22. Reynolds MR, Lane AN, Robertson B, Kemp S, Liu Y, Hill BG, Dean DC, Clem BF. Control of glutamine metabolism by the tumor suppressor Rb. Oncogene 2014;33:556-66.

23. Kuo W, Lin J, Tang TK. Human glucose-6-phosphate dehydrogenase (G6PD) gene transforms NIH 3 T3 cells and induces tumors in nude mice. Int J cancer 2000;85:857-64.

24. Wang C, Guo K, Gao D, Kang X, Jiang K, Li Y, Sun L, Zhang S, Sun C, Liu X, Wu W, Yang P, Liu Y. Identification of transaldolase as a novel serum biomarker for hepatocellular carcinoma metastasis using xenografted mouse model and clinic samples. Cancer Lett 2011;313:154-66.

25. Locasale JW, Grassian AR, Melman T, Lyssiotis CA, Mattaini KR, Bass AJ, Heffron G, Metallo CM, Muranen T, Sharfi H, Sasaki AT, Anastasiou D, Mullarky E, Vokes NI, Sasaki M, Beroukhim R, Stephanopoulos G, Ligon AH, Meyerson M, Richardson AL, Chin L, Wagner G, Asara JM, Brugge JS, Cantley LC, Vander Heiden MG. Phosphoglycerate dehydrogenase diverts glycolytic flux and contributes to oncogenesis. Nat Genet 2011;43:869-74.

26. Possemato R, Marks KM, Shaul YD, Pacold ME, Kim D, Birsoy K, Sethumadhavan S, Woo HK, Jang HG, Jha AK, Chen WW, Barrett FG, Stransky N, Tsun ZY, Cowley GS, Barretina J, Kalaany NY, Hsu PP, Ottina K, Chan AM, Yuan B, Garraway LA, Root DE, MinoKenudson M, Brachtel EF, Driggers EM, Sabatini DM. Functional genomics reveal that the serine synthesis pathway is essential in breast cancer. Nature 2011;476:346-50.

27. Bauer DE, Hatzivassiliou G, Zhao F, Andreadis C, Thompson CB. ATP citrate lyase is an important component of cell growth and transformation. Oncogene 2005;24:6314-22.

28. Hatzivassiliou G, Zhao F, Bauer DE, Andreadis C, Shaw AN, Dhanak D, Hingorani SR, Tuveson DA, Thompson CB. ATP citrate lyase inhibition can suppress tumor cell growth. Cancer Cell 2005;8:311-21.

29. Berwick DC, Hers I, Heesom KJ, Moule SK, Tavare JM. The identification of ATP-citrate lyase as a protein kinase B (Akt) substrate in primary adipocytes. J Biol Chem 2002;277:33895-900.

30. Birsoy K, Wang T, Chen WW, Freinkman E, Abu-Remaileh M, Sabatini DM. An essential role of the mitochondrial electron transport chain in cell proliferation is to enable aspartate synthesis. Cell 2015;162:540-51.

31. Sullivan LB, Gui DY, Hosios AM, Bush LN, Freinkman E, Vander Heiden MG. Supporting aspartate biosynthesis is an essential function of respiration in proliferating cells. Cell 2015;162:552-63.

32. DeBerardinis RJ, Mancuso A, Daikhin E, Nissim I, Yudkoff M, Wehrli S, Thompson CB. Beyond aerobic glycolysis: transformed cells can engage in glutamine metabolism that exceeds the requirement for protein and nucleotide synthesis. Proc Natl Acad Sci U S A 2007;104:19345-50.

33. Yuneva M, Zamboni N, Oefner P, Sachidanandam R, Lazebnik Y. Deficiency in glutamine but not glucose induces MYC-dependent apoptosis in human cells. J Cell Biol 2007;178:93-105.

34. Metallo CM, Gameiro PA, Bell EL, Mattaini KR, Yang J, Hiller K, Jewell CM, Johnson ZR, Irvine DJ, Guarente L, Kelleher JK, Vander Heiden MG, Iliopoulos O, Stephanopoulos G. Reductive glutamine metabolism by IDH1 mediates lipogenesis under hypoxia. Nature 2011;481:380-4.

35. Brosnan JT. Interorgan amino acid transport and its regulation. J Nutr 2003;133:2068S-72S.

36. Wang JB, Erickson JW, Fuji R, Ramachandran S, Gao P, Dinavahi R, Wilson KF, Ambrosio AL, Dias SM, Dang CV, Cerione RA. Targeting mitochondrial glutaminase activity inhibits oncogenic transformation. Cancer Cell 2010;18:207-19.

37. Krebs HA. Metabolism of amino-acids: the synthesis of glutamine from glutamic acid and ammonia, and the enzymic hydrolysis of glutamine in animal tissues. Biochem J 1935;29:1951-69.

38. Yielding KL, Tomkins GM. An effect of L-leucine and other essential amino acids on the structure and activity of glutamic dehydrogenase. Proc Natl Acad Sci U S A 1961;47:983-9.

39. Long J, Lang ZW, Wang HG, Wang TL, Wang BE, Liu SQ. Glutamine synthetase as an early marker for hepatocellular carcinoma based on proteomic analysis of resected small hepatocellular carcinomas. Hepatobiliary Pancreat Dis Int 2010;9:296-305.

40. Rosati A, Poliani PL, Todeschini A, Cominelli M, Medicina D, Cenzato M, Simoncini EL, Magrini SM, Buglione M, Grisanti S, Padovani A. Glutamine synthetase expression as a valuable marker of epilepsy and longer survival in newly diagnosed glioblastoma multiforme. Neuro Oncol 2013;15:618-25.

41. Gameiro PA, Yang J, Metelo AM, Pérez-Carro R, Baker R, Wang Z, Arreola A, Rathmell WK, Olumi A, López-Larrubia P, Stephanopoulos G, Iliopoulos O. In vivo HIF-mediated reductive carboxylation is regulated by citrate levels and sensitizes VHL-deficient cells to glutamine deprivation. Cell Metab 2013;17:372-85. 
42. Jiang L, Shestov AA, Swain P, Yang C, Parker SJ, Wang QA, Terada LS, Adams ND, McCabe MT, Pietrak B, Schmidt S, Metallo CM, Dranka BP, Schwartz B, DeBerardinis RJ. Reductive carboxylation supports redox homeostasis during anchorage-independent growth. Nature 2016;532:255-8.

43. Mullen AR, Wheaton WW, Jin ES, Chen PH, Sullivan LB, Cheng T, Yang Y, Linehan WM, Chandel NS, DeBerardinis RJ. Reductive carboxylation supports growth in tumour cells with defective mitochondria. Nature 2011;481:385-8.

44. Patel D, Menon D, Bernfeld E, Mroz V, Kalan S, Loayza D, Foster DA. Aspartate rescues S-phase arrest caused by suppression of glutamine utilization in KRas-driven cancer cells. J Biol Chem 2016;291:9322-9.

45. Zhang J, Fan J, Venneti S, Cross JR, Takagi T, Bhinder B, Djaballah H, Kanai M, Cheng EH, Judkins AR, Pawel B, Baggs J, Cherry $\mathrm{S}$, Rabinowitz JD, Thompson CB. Asparagine plays a critical role in regulating cellular adaptation to glutamine depletion. Mol Cell 2014;56:205-18.

46. Hao Y, Samuels Y, Li Q, Krokowski D, Guan BJ, Wang C, Jin Z, Dong B, Cao B, Feng X, Xiang M, Xu C, Fink S, Meropol NJ, Xu Y, Conlon RA, Markowitz S, Kinzler KW, Velculescu VE, Brunengraber H, Willis JE, LaFramboise T, Hatzoglou M, Zhang GF, Vogelstein B, Wang Z. Oncogenic PIK3CA mutations reprogram glutamine metabolism in colorectal cancer. Nat Commun 2016;7:11971.

47. Xu P, Oosterveer MH, Stein S, Demagny H, Ryu D, Moullan N, Wang X, Can E, Zamboni N, Comment A, Auwerx J, Schoonjans K. LRH-1-dependent programming of mitochondrial glutamine processing drives liver cancer. Genes Dev 2016;30:1255-60.

48. Vié N, Copois V, Bascoul-Mollevi C, Denis V, Bec N, Robert B, Fraslon C, Conseiller E, Molina F, Larroque C, Martineau P, Del Rio M, Gongora C. Overexpression of phosphoserine aminotransferase PSAT1 stimulates cell growth and increases chemoresistance of colon cancer cells. Mol Cancer 2008;7:14.

49. Liu W, Le A, Hancock C, Lane AN, Dang CV, Fan TW, Phang JM. Reprogramming of proline and glutamine metabolism contributes to the proliferative and metabolic responses regulated by oncogenic transcription factor c-MYC. Proc Natl Acad Sci U S A 2012;109:89838.

50. Li H, Meininger CJ, Bazer FW, Wu G. Intracellular sources of ornithine for polyamine synthesis in endothelial cells. Amino Acids 2016;48:2401-10

51. Altman BJ, Stine ZE, Dang CV. From Krebs to clinic: glutamine metabolism to cancer therapy. Nat Rev Cancer 2016;16:619-34.

52. Hosios AM, Hecht VC, Danai LV, Johnson MO, Rathmell JC, Steinhauser ML, Manalis SR, Vander Heiden MG. Amino acids rather than glucose account for the majority of cell mass in proliferating mammalian cells. Dev Cell 2016;36:540-9.

53. Xiang L, Xie G, Liu C, Zhou J, Chen J, Yu S, Li J, Pang X, Shi H, Liang H. Knock-down of glutaminase 2 expression decreases glutathione, NADH, and sensitizes cervical cancer to ionizing radiation. Biochim Biophys Acta 2013;1833:2996-3005.

54. Timmerman LA, Holton T, Yuneva M, Louie RJ, Padró M, Daemen A, Hu M, Chan DA, Ethier SP, van’t Veer LJ, Polyak K, McCormick F, Gray JW. Glutamine sensitivity analysis identifies the $\mathrm{xCT}$ antiporter as a common triple-negative breast tumor therapeutic target. Cancer Cell 2013;24:450-65.

55. Tsuchihashi K, Okazaki S, Ohmura M, Ishikawa M, Sampetrean O, Onishi N, Wakimoto H, Yoshikawa M, Seishima R, Iwasaki Y, Morikawa T, Abe S, Takao A, Shimizu M, Masuko T, Nagane M, Furnari FB, Akiyama T, Suematsu M, Baba E, Akashi K, Saya H, Nagano O. The EGF receptor promotes the malignant potential of glioma by regulating amino acid transport system xc(-). Cancer Res 2016;76:2954-63.

56. Koppula P, Zhang Y, Shi J, Li W, Gan B. The glutamate/cystine antiporter SLC7A11/xCT enhances cancer cell dependency on glucose by exporting glutamate. J Biol Chem 2017;292:14240-9.

57. Sayin VI, LeBoeuf SE, Singh SX, Davidson SM, Biancur D, Guzelhan BS, Alvarez SW, Wu WL, Karakousi TR, Zavitsanou AM, Ubriaco J, Muir A, Karagiannis D, Morris PJ, Thomas CJ, Possemato R, Vander Heiden MG, Papagiannakopoulos T. Activation of the NRF2 antioxidant program generates an imbalance in central carbon metabolism in cancer. Elife 2017; doi: 10.7554/eLife.28083.

58. Shin CS, Mishra P, Watrous JD, Carelli V, D’Aurelio M, Jain M, Chan DC. The glutamate/cystine xCT antiporter antagonizes glutamine metabolism and reduces nutrient flexibility. Nat Commun 2017;8:15074.

59. Son J, Lyssiotis CA, Ying H, Wang X, Hua S, Ligorio M, Perera RM, Ferrone CR, Mullarky E, Shyh-Chang N, Kang Y, Fleming JB, Bardeesy N, Asara JM, Haigis MC, DePinho RA, Cantley LC, Kimmelman AC. Glutamine supports pancreatic cancer growth through a KRAS-regulated metabolic pathway. Nature 2013;496:101-5.

60. Figueroa ME, Abdel-Wahab O, Lu C, Ward PS, Patel J, Shih A, Li Y, Bhagwat N, Vasanthakumar A, Fernandez HF, Tallman MS, Sun Z, Wolniak K, Peeters JK, Liu W, Choe SE, Fantin VR, Paietta E, Löwenberg B, Licht JD, Godley LA, Delwel R, Valk PJ, Thompson CB, Levine RL, Melnick A. Leukemic IDH1 and IDH2 mutations result in a hypermethylation phenotype, disrupt TET2 function, and impair hematopoietic differentiation. Cancer Cell 2010;18:553-67.

61. Ward PS, Patel J, Wise DR, Abdel-Wahab O, Bennett BD, Coller HA, Cross JR, Fantin VR, Hedvat CV, Perl AE, Rabinowitz JD, Carroll M, Su SM, Sharp KA, Levine RL, Thompson CB. The common feature of leukemia-associated IDH1 and IDH2 mutations is a neomorphic enzyme activity converting alpha-ketoglutarate to 2-hydroxyglutarate. Cancer Cell 2010;17:225-34.

62. Letouzé E, Martinelli C, Loriot C, Burnichon N, Abermil N, Ottolenghi C, Janin M, Menara M, Nguyen AT, Benit P, Buffet A, Marcaillou C, Bertherat J, Amar L, Rustin P, De Reyniès A, Gimenez-Roqueplo AP, Favier J. SDH mutations establish a hypermethylator phenotype in paraganglioma. Cancer Cell 2013;23:739-52.

63. Xiao M, Yang H, Xu W, Ma S, Lin H, Zhu H, Liu L, Liu Y, Yang C, Xu Y, Zhao S, Ye D, Xiong Y, Guan KL. Inhibition of a-KG-dependent histone and DNA demethylases by fumarate and succinate that are accumulated in mutations of FH and SDH tumor suppressors. Genes Dev 2012;26:1326-38

64. Pan M, Reid MA, Lowman XH, Kulkarni RP, Tran TQ, Liu X, Yang Y, Hernandez-Davies JE, Rosales KK, Li H, Hugo W, Song C, Xu X, Schones DE, Ann DK, Gradinaru V, Lo RS, Locasale JW, Kong M. Regional glutamine deficiency in tumours promotes dedifferentia- 
tion through inhibition of histone demethylation. Nat Cell Biol 2016;18:1090-101.

65. van Geldermalsen M, Wang Q, Nagarajah R, Marshall AD, Thoeng A, Gao D, Ritchie W, Feng Y, Bailey CG, Deng N, Harvey K, Beith JM, Selinger CI, O’Toole SA, Rasko JE, Holst J. ASCT2/SLC1A5 controls glutamine uptake and tumour growth in triple-negative basal-like breast cancer. Oncogene 2016;35:3201-8.

66. Bröer A, Rahimi F, Bröer S. Deletion of amino acid transporter ASCT2 (SLC1A5) reveals an essential role for transporters SNAT1 (SLC38A1) and SNAT2 (SLC38A2) to sustain glutaminolysis in cancer cells. J Biol Chem 2016;291:13194-205.

67. Polletta L, Vernucci E, Carnevale I, Arcangeli T, Rotili D, Palmerio S, Steegborn C, Nowak T, Schutkowski M, Pellegrini L, Sansone L, Villanova L, Runci A, Pucci B, Morgante E, Fini M, Mai A, Russo MA, Tafani M. SIRT5 regulation of ammonia-induced autophagy and mitophagy. Autophagy 2015;11:253-70.

68. Masamha CP, Xia Z, Yang J, Albrecht TR, Li M, Shyu AB, Li W, Wagner EJ. CFIm25 links alternative polyadenylation to glioblastoma tumour suppression. Nature 2014;510:412-6.

69. Redis RS, Vela LE, Lu W, Ferreira de Oliveira J, Ivan C, Rodriguez-Aguayo C, Adamoski D, Pasculli B, Taguchi A, Chen Y, Fernandez AF, Valledor L, Van Roosbroeck K, Chang S, Shah M, Kinnebrew G, Han L, Atlasi Y, Cheung LH, Huang GY, Monroig P, Ramirez MS, Catela Ivkovic T, Van L, Ling H, Gafà R, Kapitanovic S, Lanza G, Bankson JA, Huang P, Lai SY, Bast RC, Rosenblum MG, Radovich M, Ivan M, Bartholomeusz G, Liang H, Fraga MF, Widger WR, Hanash S, Berindan-Neagoe I, Lopez-Berestein G, Ambrosio ALB, Gomes Dias SM, Calin GA. Allele-specific reprogramming of cancer metabolism by the long non-coding RNA CCAT2. Mol Cell 2016;61:52034.

70. Colombo SL, Palacios-Callender M, Frakich N, Carcamo S, Kovacs I, Tudzarova S, Moncada S. Molecular basis for the differential use of glucose and glutamine in cell proliferation as revealed by synchronized HeLa cells. Proc Natl Acad Sci U S A 2011;108:21069-74.

71. Fahien LA, Kmiotek E. Regulation of glutamate dehydrogenase by palmitoyl-coenzyme A. Arch Biochem Biophys 1981;212:247-53.

72. Frieden C. Glutamate dehydrogenase. V. The relation of enzyme structure to the catalytic function. J Biol Chem 1963;238:3286-99.

73. Tomita T, Kuzuyama T, Nishiyama M. Structural basis for leucine-induced allosteric activation of glutamate dehydrogenase. J Biol Chem 2011;286:37406-13.

74. Haigis MC, Mostoslavsky R, Haigis KM, Fahie K, Christodoulou DC, Murphy AJ, Valenzuela DM, Yancopoulos GD, Karow M, Blander G, Wolberger C, Prolla TA, Weindruch R, Alt FW, Guarente L. SIRT4 inhibits glutamate dehydrogenase and opposes the effects of calorie restriction in pancreatic beta cells. Cell 2006;126:941-54.

75. Wang Y, Fan S, Lu J, Zhang Z, Wu D, Wu Z, Zheng Y. GLUL promotes cell proliferation in breast cancer. J Cell Biochem 2017;118:2018-25.

76. van der Vos KE, Eliasson P, Proikas-Cezanne T, Vervoort SJ, van Boxtel R, Putker M, van Zutphen IJ, Mauthe M, Zellmer S, Pals C, Verhagen LP, Groot Koerkamp MJ, Braat AK, Dansen TB, Holstege FC, Gebhardt R, Burgering BM, Coffer PJ. Modulation of glutamine metabolism by the PI(3)K-PKB-FOXO network regulates autophagy. Nat Cell Biol 2012;14:829-37.

77. Bott AJ, Peng IC, Fan Y, Faubert B, Zhao L, Li J, Neidler S, Sun Y, Jaber N, Krokowski D, Lu W, Pan JA, Powers S, Rabinowitz J, Hatzoglou M, Murphy DJ, Jones R, Wu S, Girnun G, Zong WX. Oncogenic myc induces expression of glutamine synthetase through promoter demethylation. Cell Metab 2015;22:1068-77.

78. Cox AG, Hwang KL, Brown KK, Evason K, Beltz S, Tsomides A, O’Connor K, Galli GG, Yimlamai D, Chhangawala S, Yuan M, Lien EC, Wucherpfennig J, Nissim S, Minami A, Cohen DE, Camargo FD, Asara JM, Houvras Y, Stainier DYR, Goessling W. Yap reprograms glutamine metabolism to increase nucleotide biosynthesis and enable liver growth. Nat Cell Biol 2016;18:886-96.

79. Arad G, Freikopf A, Kulka RG. Glutamine-stimulated modification and degradation of glutamine synthetase in hepatoma tissue culture cells. Cell 1976;8:95-101.

80. Demars R. The inhibition by glutamine of glutamyl transferase formation in cultures of human cells. Biochim Biophys Acta 1958;27:435-6.

81. Nguyen TV, Lee JE, Sweredoski MJ, Yang SJ, Jeon SJ, Harrison JS, Yim JH, Lee SG, Handa H, Kuhlman B, Jeong JS, Reitsma JM, Park CS, Hess S, Deshaies RJ. Glutamine triggers acetylation-dependent degradation of glutamine synthetase via the thalidomide receptor cereblon. Mol Cell 2016;61:809-20.

82. Abu Aboud O, Habib SL, Trott J, Stewart B, Liang S, Chaudhari AJ, Sutcliffe J, Weiss RH. Glutamine addiction in kidney cancer suppresses oxidative stress and can be exploited for real-time imaging. Cancer Res 2017;77:6746-58.

83. Petronini PG, Urbani S, Alfieri R, Borghetti AF, Guidotti GG. Cell susceptibility to apoptosis by glutamine deprivation and rescue: survival and apoptotic death in cultured lymphoma-leukemia cell lines. J Cell Physiol 1996;169:175-85.

84. Weinberg F, Hamanaka R, Wheaton WW, Weinberg S, Joseph J, Lopez M, Kalyanaraman B, Mutlu GM, Budinger GR, Chandel NS. Mitochondrial metabolism and ROS generation are essential for Kras-mediated tumorigenicity. Proc Natl Acad Sci U S A 2010;107:878893.

85. Tardito S, Oudin A, Ahmed SU, Fack F, Keunen O, Zheng L, Miletic H, Sakariassen PØ, Weinstock A, Wagner A, Lindsay SL, Hock AK, Barnett SC, Ruppin E, Mørkve SH, Lund-Johansen M, Chalmers AJ, Bjerkvig R, Niclou SP, Gottlieb E. Glutamine synthetase activity fuels nucleotide biosynthesis and supports growth of glutamine-restricted glioblastoma. Nat Cell Biol 2015;17:1556-68.

86. Pavlova NN, Hui S, Ghergurovich JM, Fan J, Intlekofer AM, White RM, Rabinowitz JD, Thompson CB, Zhang J. As extracellular glutamine levels decline, asparagine becomes an essential amino acid. Cell Metab 2018;27:428-38.

87. Krall AS, Xu S, Graeber TG, Braas D, Christofk HR. Asparagine promotes cancer cell proliferation through use as an amino acid exchange factor. Nat Commun 2016;7:11457.

88. Durán RV, Oppliger W, Robitaille AM, Heiserich L, Skendaj R, Gottlieb E, Hall MN. Glutaminolysis activates Rag-mTORC1 signaling. Mol Cell 2012;47:349-58. 
89. Durán RV, MacKenzie ED, Boulahbel H, Frezza C, Heiserich L, Tardito S, Bussolati O, Rocha S, Hall MN, Gottlieb E. HIF-independent role of prolyl hydroxylases in the cellular response to amino acids. Oncogene 2013;32:4549-56.

90. Jewell JL, Kim YC, Russell RC, Yu FX, Park HW, Plouffe SW, Tagliabracci VS, Guan KL. Metabolism. Differential regulation of mTORC1 by leucine and glutamine. Science 2015;347:194-8.

91. Tan HWS, Sim AYL, Long YC. Glutamine metabolism regulates autophagy-dependent mTORC1 reactivation during amino acid starvation. Nat Commun 2017;8:338.

92. Villar VH, Nguyen TL, Delcroix V, Terés S, Bouchecareilh M, Salin B, Bodineau C, Vacher P, Priault M, Soubeyran P, Durán RV. mTORC1 inhibition in cancer cells protects from glutaminolysis-mediated apoptosis during nutrient limitation. Nat Commun 2017;8:14124.

93. Csibi A, Fendt SM, Li C, Poulogiannis G, Choo AY, Chapski DJ, Jeong SM, Dempsey JM, Parkhitko A, Morrison T, Henske EP, Haigis MC, Cantley LC, Stephanopoulos G, Yu J, Blenis J. The mTORC1 pathway stimulates glutamine metabolism and cell proliferation by repressing SIRT4. Cell 2013;153:840-54.

94. Jeong SM, Xiao C, Finley LW, Lahusen T, Souza AL, Pierce K, Li YH, Wang X, Laurent G, German NJ, Xu X, Li C, Wang RH, Lee J, Csibi A, Cerione R, Blenis J, Clish CB, Kimmelman A, Deng CX, Haigis MC. SIRT4 has tumor-suppressive activity and regulates the cellular metabolic response to DNA damage by inhibiting mitochondrial glutamine metabolism. Cancer Cell 2013;23:450-63.

95. Csibi A, Lee G, Yoon SO, Tong H, Ilter D, Elia I, Fendt SM, Roberts TM, Blenis J. The mTORC1/S6K1 pathway regulates glutamine metabolism through the eIF4B-dependent control of c-Myc translation. Curr Biol 2014;24:2274-80.

96. Coloff JL, Murphy JP, Braun CR, Harris IS, Shelton LM, Kami K, Gygi SP, Selfors LM, Brugge JS. Differential glutamate metabolism in proliferating and quiescent mammary epithelial cells. Cell Metab 2016;23:867-80.

97. White MA, Lin C, Rajapakshe K, Dong J, Shi Y, Tsouko E, Mukhopadhyay R, Jasso D, Dawood W, Coarfa C, Frigo DE. Glutamine transporters are targets of multiple oncogenic signaling pathways in prostate cancer. Mol Cancer Res 2017;15:1017-28.

98. Scalise M, Pochini L, Galluccio M, Indiveri C. Glutamine transport. From energy supply to sensing and beyond. Biochim Biophys Acta 2016;1857:1147-57.

99. Tanaka K, Sasayama T, Irino Y, Takata K, Nagashima H, Satoh N, Kyotani K, Mizowaki T, Imahori T, Ejima Y, Masui K, Gini B, Yang H, Hosoda K, Sasaki R, Mischel PS, Kohmura E. Compensatory glutamine metabolism promotes glioblastoma resistance to mTOR inhibitor treatment. J Clin Invest 2015;125:1591-602.

100. Robinson MM, McBryant SJ, Tsukamoto T, Rojas C, Ferraris DV, Hamilton SK, Hansen JC, Curthoys NP. Novel mechanism of inhibition of rat kidney-type glutaminase by bis-2-(5-phenylacetamido-1,2,4-thiadiazol-2-yl)ethyl sulfide (BPTES). Biochem J 2007;406:40714.

101. Gross MI, Demo SD, Dennison JB, Chen L, Chernov-Rogan T, Goyal B, Janes JR, Laidig GJ, Lewis ER, Li J, Mackinnon AL, Parlati F, Rodriguez ML, Shwonek PJ, Sjogren EB, Stanton TF, Wang T, Yang J, Zhao F, Bennett MK. Antitumor activity of the glutaminase inhibitor CB-839 in triple-negative breast cancer. Mol Cancer Ther 2014;13:890-901.

102. Jacque N, Ronchetti AM, Larrue C, Meunier G, Birsen R, Willems L, Saland E, Decroocq J, Maciel TT, Lambert M, Poulain L, Hospital MA, Sujobert P, Joseph L, Chapuis N, Lacombe C, Moura IC, Demo S, Sarry JE, Recher C, Mayeux P, Tamburini J, Bouscary D. Targeting glutaminolysis has antileukemic activity in acute myeloid leukemia and synergizes with BCL-2 inhibition. Blood 2015;126:134656.

103. Korangath P, Teo WW, Sadik H, Han L, Mori N, Huijts CM, Wildes F, Bharti S, Zhang Z, Santa-Maria CA, Tsai H, Dang CV, Stearns V, Bhujwalla ZM, Sukumar S. Targeting glutamine metabolism in breast cancer with aminooxyacetate. Clin Cancer Res 2015;21:3263-73.

104. Li M, Allen A, Smith TJ. High throughput screening reveals several new classes of glutamate dehydrogenase inhibitors. Biochemistry 2007;46:15089-102.

105. Qing G, Li B, Vu A, Skuli N, Walton ZE, Liu X, Mayes PA, Wise DR, Thompson CB, Maris JM, Hogarty MD, Simon MC. ATF4 regulates MYC-mediated neuroblastoma cell death upon glutamine deprivation. Cancer Cell 2012;22:631-44.

106. Cheng T, Sudderth J, Yang C, Mullen AR, Jin ES, Matés JM, DeBerardinis RJ. Pyruvate carboxylase is required for glutamine-independent growth of tumor cells. Proc Natl Acad Sci U S A 2011;108:8674-9.

107. Christen S, Lorendeau D, Schmieder R, Broekaert D, Metzger K, Veys K, Elia I, Buescher JM, Orth MF, Davidson SM, Grünewald TG, De Bock K, Fendt SM. Breast cancer-derived lung metastases show increased pyruvate carboxylase-dependent anaplerosis. Cell Rep 2016;17:837-48.

108. Linares JF, Cordes T, Duran A, Reina-Campos M, Valencia T, Ahn CS, Castilla EA, Moscat J, Metallo CM, Diaz-Meco MT. ATF4induced metabolic reprograming is a synthetic vulnerability of the p62-deficient tumor stroma. Cell Metab 2017;26:817-29. 